Nadja Bartol

\title{
Poslednja sodba $v$ špitalski cerkvi sv. Duha v Slovenj Gradcu kot likovni medij sovpadanja stvarnega in metafizičnega
}

Ključne besede: poslednja sodba, špitalska cerkev sv. Duha, Andachtsbild, špital

DOI: 10.4312 /ars.8.2.228-240

$\mathrm{Z}$ razvojem mistike in religioznim gibanjem devotio moderna je mogoče $\mathrm{v}$ zahodnoevropskem slikarstvu zaslediti tudi razvoj nabožnega slikarstva, v okviru katerega so se pojavile funkciji ikon podobne umetnine, namenjene meditaciji in kontemplaciji. Zanimive so zlasti $z$ estetskega vidika, saj vedno znova odpirajo vprašanja o svoji funkciji, predvsem pa o načinu komuniciranja z gledalcem. Temelje raziskav sta v 19. stoletju zastavila Franz Kugler (Kugler, 1837) in Karl Schnaase (Schnaase, 1861) ter tovrstne umetnine glede na formo in upodobljen motiv poimenovala s terminom Andachtsbilder. Čeprav jih je že Schnaase povezal tudi z njihovo namembnostjo in s tem opozoril, da niti forma niti upodobljen motiv ni ustrezno merilo za njihovo opredelitev, jih je sistematično obdelal in klasificiral šele Panofsky (Panofsky, 1927). Razlikoval je med reprezentativno in nabožno podobo ter s terminom Andachtsbild označil tiste, pri katerih gre za izločitev posameznih motivov iz scenskih historiae, ki so kot take v gledalcu vzbujale sočutje. $S$ tem je tovrstne umetnine, glede na upodobljen motiv in namembnost, ločil od ostalih sakralnih upodobitev. Vendar pa je pri tem upošteval le umetnine manjšega formata, namenjene osebni rabi. Temu nasprotno so rezultati novejših raziskav, upoštevajoč kriterij namembnosti, pokazali, da so funkcijo meditativnega poglabljanja $\mathrm{v}$ upodobljeno vsebino imele tudi večje upodobitve javnega značaja, kot so oltarne podobe (Berliner, 1955) in stenske poslikave, v tem primeru celo stenske historiae (Ringbom, 1984). S tem so se ponovno odprla vprašanja o kriterijih za opredelitev tovrstnih umetnin, predvsem pa je bila zamajana sprejeta in uveljavljena klasifikacija Panofskega. Zaradi neustreznega instrumentarija, s katerim bi tovrstne umetnine terminološko opredelili, in zaradi vprašanja, ali je v zvezi z njimi sploh mogoče govoriti o samostojni zvrsti oziroma tipih umetnin, pa se polemike odvijajo še danes.

V slovenskem prostoru te problematike ni posebej izpostavljal nihče. Termin je mogoče zaslediti pri Steletu (Stele, 1934), ki je povzel po Panofskem zastavljeno klasifikacijo

nabožnih umetnin in tako pod terminom Andachtsbild prepoznal tiste umetnine, ki so ponujale možnost kontemplativne poglobitve vernika v upodobljeno vsebino (Stele, 1934, 
138), ter z njihovo funkcijo povezan lirični slog upodobitve (Stele, 1934, 142, 143). Hkrati je poudaril, da samo področje sakralne umetnosti v slovenskem prostoru ni ne zadosti raziskano ne terminološko dovolj natančno opredeljeno (Stele, 1934, 119).

Med tovrstne umetnine sodi tudi upodobitev poslednje sodbe (Poslednja sodba, ok. 1500, špitalska cerkev sv. Duha, Slovenj Gradec) neznanega, a domnevno lokalnega mojstra. Njen nastanek sega v čas okoli leta 1500. Upodobitev poslednje sodbe krasi ladijsko stran slavoločne stene $\mathrm{v}$ nekdanji kapeli, ki je bila nato $\mathrm{v}$ dveh fazah - že v 15. stoletju - prezidana v majhno špitalsko cerkev (Curk, 1986, 330). Čeprav je freska precej poškodovana, je motiv kljub temu, z vsemi svojimi ikonografskimi elementi, še prepoznaven. Vendar pa poslikava v okviru sakralnega figurativnega slikarstva predstavlja le eno izmed poenostavljenih variacij motiva, ki vključuje zgolj najosnovnejše ikonografske prvine ter tako s skopo likovno retoriko in slogovno preprostostjo scenske historiae prikazuje upodobljeno teološko resnico. A ker umetnina niti $\mathrm{z}$ estetskega niti $\mathrm{z}$ ikonografskega vidika ne predstavlja posebne vrednosti, pri umetnostnih zgodovinarjih ni pritegnila pozornosti. Njena vrednost se razkriva šele skozi funkcijo, ki jo je kot Andachtsbild odigrala v času delovanja špitala. Namen pričujočega članka je osvetliti prav to funkcijo, zaradi katere pa freska pridobiva tako na pomenu kot tudi na vrednosti (Sliki 1 in 2).

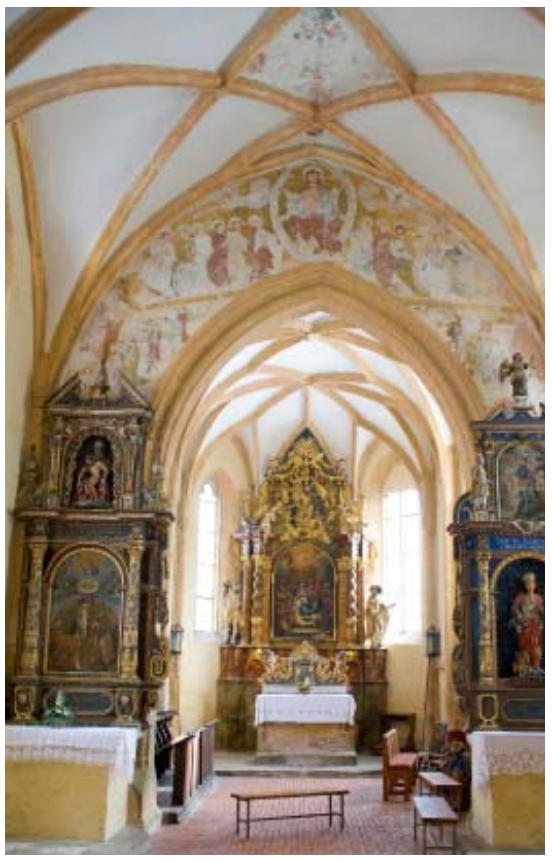

Slika 1: Špitalska cerkev sv. Duha, Slovenj Gradec. Fotografija: Nejc Radoševič 


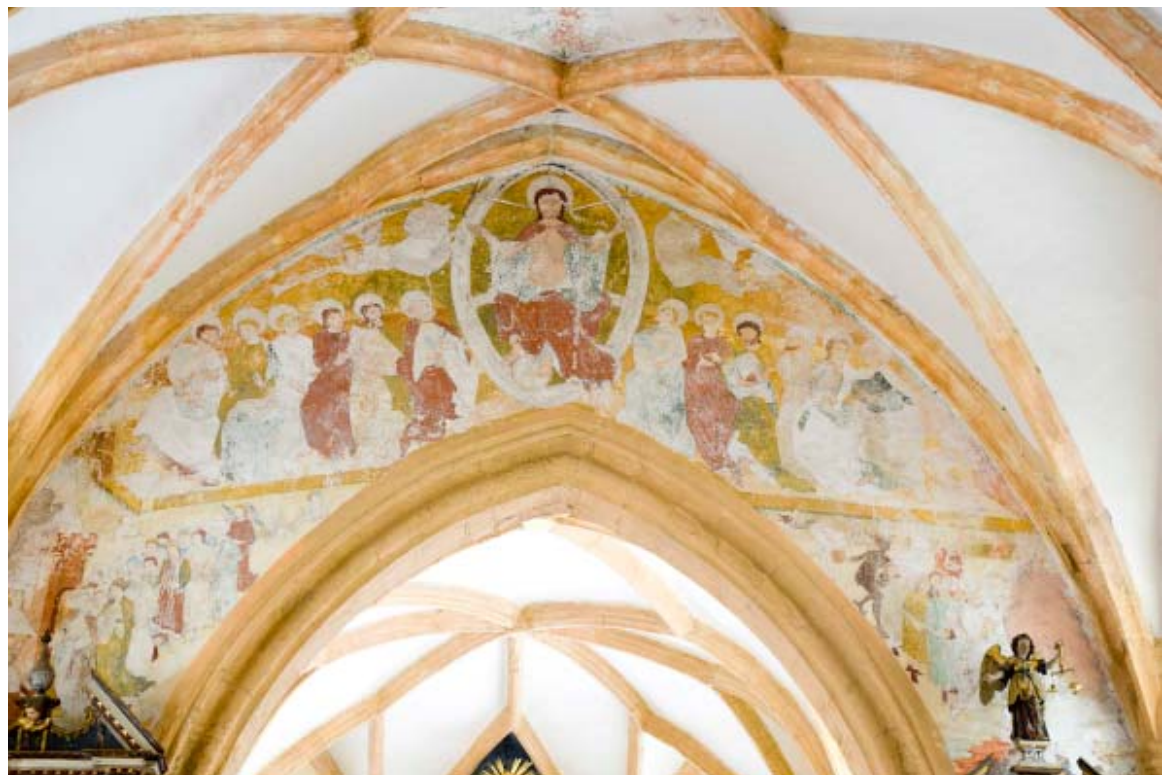

Slika 2: Poslednja sodba, ok. 1500, špitalska cerkev sv. Duha, Slovenj Gradec. Fotografija: Nejc Radoševič

Najpodrobneje in najobsežneje jo, čeprav jo $\mathrm{v}$ okviru študije, ki temelji na podlagi ohranjenih listin o nastanku špitala in pozidavi kapele, omenja tudi Jože Mlinarič (Mlinarič, 1986, 315-327; Mlinarič, 1985, 7-14), opiše Jože Curk (Curk, 1986, 327-334; Curk, 1985, 15-24), ki tako kot Höfler (Höfler, 2004, 189) poda tudi njen ikonografski opis - medtem ko je v okviru drugih, splošnih in preglednih študij slovenskega gotskega stenskega slikarstva komajda omenjena in zgolj zavedena ali celo preprosto izpuščena. Ker tudi o cerkvi sv. Duha ter o izvajanju liturgije in delovanju špitala ni veliko ohranjenih podatkov, je študija ob ohranjenih virih, med drugim tudi ustanovni listini špitala, zgrajena na primerjavi raziskav o delovanju drugih, sočasnih tovrstnih ustanov v zahodnoevropskem prostoru.

Umetnina $\mathrm{v}$ slogu poznogotskega realizma prikazuje $\mathrm{z}$ lilijo in mečem $\mathrm{v}$ ustih upodobljenega Kristusa v mandorli, ki z navzven odprtimi dlanmi kaže rane križanja. Osrednjo figuro na vsaki strani obdaja angel $s$ trobento, oba pa pozivata mrtve $\mathrm{k}$ vstajenju. Pod Kristusom je nanizanih dvanajst apostolov, na vsaki strani šest, medtem ko v zadnji vrsti pod njimi peklenšček - na Kristusovi levi strani - naganja grešne duše v peklensko žrelo, na njegovi desni pa angel izvoljene vodi v nebeški Jeruzalem, upodobljen v podobi gradu.

Upodobljena na ladijski strani slavoloka, daje mistično kvaliteto arhitekturnemu elementu, kjer v funkciji pajčolana, ki ločuje zemeljski svet od onstranstva, posvečen 
prostor od laičnega, poudarja marginalno funkcijo slavoloka. Hkrati izpostavlja Kristusa kot vrata, skozi katera blažene duše stopajo v nebeško kraljestvo. Lilija in meč ponazarjata njegovo funkcijo eshatološkega sodnika, medtem ko njegova podoba $z$ navzven odprtimi dlanmi, ki kaže rane križanja, pri tem opozarja, da je za odrešenje potrebno popolno sprejemanje vere, pri čemer se obljuba blaženosti v nebeškem kraljestvu v tem kontekstu izključno nanaša na duhovne darove.

Doktrinarna vsebina, ki jo upodablja umetnina, sodi v samo osrčje krščanske eshatologije. Zasledimo jo $\mathrm{v}$ številnih svetopisemskih odlomkih, tako Stare kot tudi Nove zaveze. Njen koncept, ki zajema verovanje v nesmrtnost duše, je prežet $\mathrm{z}$ močno moralistično noto. Ta $\mathrm{v}$ Novi zavezi napoveduje konec sveta, dan, ko bo zapečatena usoda vsake posamezne duše, ter tako označuje dogodek vstajenja mrtvih in živih, ki pravičnim prinaša mir in spokoj v blaženosti večnega življenja, grešnim pa večne muke in trpljenje v peklu. Kot zadnja vez med časom in večnostjo na eni strani odmeva $\mathrm{v}$ strahu pred sodbo, na drugi pa $\mathrm{v}$ upanju na prihajajočo odrešitev; tako odpira vprašanja o dobrem in zlu, čistosti in grehu ter pomenu in smislu človekovega bivanja. To je v okviru krščanske doktrine konceptualizirano $\mathrm{v}$ nepretrgan kontinuum, $\mathrm{v}$ katerem je smrt zgolj prekinitev, nato pa $\mathrm{v}$ njegovem nadaljevanju v onstranstvu, na katerega je bilo v srednjem veku pod vplivom močno religiozno obarvane mentalitete osredotočeno tudi samo zemeljsko bivanje. Tako je dojemanje smrti $\mathrm{v}$ tem kontekstu mogoče interpretirati le kot vrata $\mathrm{v}$ večnost, kjer duša kljub raztelešenju ohranja kapaciteto somatskega trpljenja, prehodno v vicah in trajno v peklu, ter čutnega doživljanja duhovnih blaženosti nebeškega kraljestva, kar pa je metafizičnim svetovom onkraj zemeljske eksistence dalo izjemno stvarno podobo. Ključna vloga, ki jo je pri tem odigrala Cerkev, pa ni bila zgolj v vpeljevanju in krepitvi vere $\mathrm{v}$ neizpodbitne teološke resnice, oblikovanju in - skozi sholastično filozofijo - uveljavljanju kolektivnega dojemanja sveta kot od Boga ustvarjene naravne hierarhije, v krščanski okvir zajetega linearnega pojmovanja časa, od creatio ex nihilo do eshatološkega vrhunca, temveč zlasti v tem, da je v okviru slednjega narekovala tudi način samega življenja.

Cerkev, v kateri se umetnina nahaja, je bila $\mathrm{v}$ tesni povezavi z delovanjem špitala. Nastanki tovrstnih ustanov v slovenskem prostoru datirajo v zgodnje 14. stoletje. Sprva so jih ustanavljali meniški redovi, najpogosteje benediktinci, cistercijani in kartuzijani (Mlinarič, 1985, 7), kasneje, $\mathrm{v}$ 15. stoletju, z razvojem mest in s tem krepitvijo zavesti za stanovsko solidarnost, pa tudi meščani. Kakor priča ustanovna listina, čeprav se špital omenja že leta 1417, je bil slovenjgraški, tipa hospitale pauperum, uradno ustanovljen leta 1419. Njegov ustanovitelj je bil bogat priseljenec Johan von Lak, Janez iz Loke. Gradnja, sprva kapele, ki je sodila k vsakemu špitalu, datira v obdobje med letoma 1424 in 1428. Ta kapela ni bila višja od današnjega slavoloka. K njej so leta 
1447 prizidali še prezbiterij, ki je bil višji od prvotne kapele. Leta 1450 je Andrej iz Ottinga s sedemindvajsetimi slikami Kristusovega pasijona poslikal njegovo severno steno. Ladjo so po letu 1450 skoraj v celoti podrli in v višini prezbiterija sezidali novo. Medtem ko portal današnje cerkve nosi letnico 1494, postavljajo poslikavo poslednje sodbe na slavoloku v čas okoli leta 1500 (Curk, 1985, 18-21; Mlinarič, 1985, 7, 10; Curk, 1986, 330-332; Mlinarič, 1986, 316, 317).

Vendar pa so bili takratni špitali, čeprav namenjeni ubožnim, bolnim in oslabelim, kljub zavajajoči rabi termina, s katerim danes označujemo zdravstvene ustanove, praviloma le $\mathrm{v}$ funkciji zavetišča. Njihova temeljna naloga je bila, medtem ko je telo slabelo in je bila praksa telesnega zdravljenja bolj ali manj prepuščena sama sebi, zgolj pro cura animarum, skrb za ozdravljenje duše (Bird, 2001, 103). To pa je v krščanskem kontekstu pomenilo $\mathrm{z}$ molitvijo disciplinirati značaj in utrditi dušo v veri ter jo $\mathrm{v}$ skladu s ciljem same doktrine pripraviti na bivanje v večnosti (Lindberg, 1993, 59).

Eno izmed dejstev, ki nedvomno osvetljuje funkcijo špitalov in prevladujočo vlogo vere v procesu telesnega ozdravljenja, je zagotovo kolektivno dojemanje bolezni kot Božje kazni, ki je bila ljudem naložena zaradi izvirnega greha kot njegova neizogibna posledica. Da je bilo temu tako, je v okviru zakramenta bolniškega maziljenja potrdil tudi eden izmed sklepov, sprejetih na sinodi v Paviji že leta 850. Globoka molitev ne zagotavlja le odrešitve grehov, temveč tudi telesno ozdravljenje bolnih, kar pa je mogoče doseči le z zakramentom pokore. Ker je duša pomembnejša od telesa, kar je rimskokatoliška Cerkev na četrtem lateranskem koncilu leta 1215 v okviru enega izmed sklepov tudi uradno potrdila, je prav s tem argumentom prepovedala vse tiste medicinske posege $\mathrm{v}$ telo, $\mathrm{s}$ katerimi bi duši lahko škodovali.

Pojmovni preplet telesnega zdravljenja in globoke pobožnosti izvira že iz svetopisemskih odlomkov Nove zaveze (Mr 2, 17; Mt 9, 12; Lk 5, 31, 32). Razviden je $\mathrm{v}$ Kristusovi vlogi kot duhovnega in telesnega zdravnika. Kljub temu pa je analogija bolj zapletena, kot se razkriva na prvi pogled. V svetopisemskih pripovedih se Kristus ponekod pojavlja izključno kot telesni zdravitelj (Jn 4, 46-53; Mt 15, 30, 31; Lk 13, 10-13; Mt 20, 29-34), drugod pa kot zdravitelj duševno bolnih, grešnih in nevernih, ki se jim z oznanjanjem Božje besede in njenim sprejetjem povrne tudi telesno zdravje (Mr 2, 1-12; Jak 5, 16; Mr 16, 12; Jak 5, 14, 15). S to svojo dvojno vlogo se je Kristus uveljavil kot magnus medicus, edini pravi zdravnik telesa in duha, kakor ga je označil Ignacij Antiohijski v Pismu Efežanom, hostijo pa je v nadaljevanju pojmoval kot medicamentum immortalitatis, zdravilo nesmrtnosti. Zanimivo je, da se je tudi pojem salvator sprva nanašal tako na Kristusovo soteriološko kot tudi zdraviteljsko funkcijo, a se je kasneje, $\mathrm{z}$ oblikovanjem same doktrine, tudi terminološko uveljavil izključno z odrešenjsko konotacijo (Lukken, 1973, 304). 
Analogija zdravja in vere se je $\mathrm{v}$ času pisanja cerkvenih očetov $\mathrm{v}$ njihovih eksegetskih delih izoblikovala v metaforo Christus medicus. Čeprav jo je mogoče prvič zaslediti že pri Ignaciju Antiohijskem, se je v obliki jasno definiranega koncepta uveljavila šele v 2. stoletju - sprva v delih grških cerkvenih očetov, med drugim Klementa Aleksandrijskega (Dörnemann, 9-12) in Origena (Dörnemann, 12-16), kasneje pa tudi latinskih cerkvenih očetov, kot sta bila Tertulijan in Ciprijan, a najizraziteje v delih svetega Avguština. Ta je v svojih pridigah izjemno pomembnost pripisal globoki ponižnosti, ki jo je imel za temelj krščanske vere. V ponosu je namreč videl vzrok izvirnega greha prvih staršev (Augustini, 1838, 1.13, 16), za katerim je, kakor je interpretiral, obolelo celotno človeštvo. Prav tako je poudarjal vlogo fizičnega trpljenja (Arbesmann, 1954, 6) kot neločljive komponente in predpogoja odrešenja, kajti bil je prepričan, da varuje pred ponosom in lakomnostjo. Trpljenje, rojeno $\mathrm{v}$ duhu, lahko postane tudi oblika pokore, podobno kot prostovoljna revščina, ki so jo prakticirali nekateri meniški redovi in je po njihovem prepričanju služila izboljšanju značaja trpečih in njihovih duš (Bird, 2001, 102).

Dojemanje trpljenja kot zagotovila odrešitve pa prav tako sovpada $\mathrm{z}$ razvojem mistike - uveljavljeno versko prakso, ki se je s posnemanjem Kristusovega duhovnega življenja, imitatio Christi, prenesla tudi na njegovo fizično trpljenje. O tem zgovorno pričajo različne meditativne prakse, ki so se razvile pri nekaterih meniških redovih. Te so ob molitvi narekovale bičanje ali podobne oblike telesnega trpinčenja. Tako so verniki prek lastnega trpljenja, ki je v srednjem veku ob številnih boleznih, neprestanih vojnah in izjemno skromnem medicinskem znanju veljalo kot življenjsko dejstvo, ki ga je treba potrpežljivo in brez samopomilovanja sprejeti, ter prek ohranjanja mentalne podobe prizorov pasijona iskali duhovni napredek. Afektivni imitatio Christi je tako deloval kot neka vrsta vic, ki je obljubljala paradisum in terra, duhovno radost vsem tistim, ki so se poglobili in predali meditativni molitvi.

Izpostavljanje Kristusovega trpljenja v veri, da je prav njegova človeškost tista, ki zagotavlja odrešenje, se je $\mathrm{z}$ razvojem novih motivov izrazilo tudi $\mathrm{v}$ likovni umetnosti. Za naš kontekst je relevantno omeniti, da so ti krasili tudi stene nekaterih večjih evropskih špitalov. Tako je ena izmed še posebej zanimivih in doživetih dopasna podoba Kristusa (Kristus kaže svojo rano, ok. 1420-1425, globok relief, A.43-1937, Muzej Viktorije in Alberta, London), ki si z rokama razpira rano na boku in jo tako še izraziteje izpostavlja. Ta podoba je zapolnjevala luneto nad vrati pokopališča špitala Santa Maria Nuova v Firencah (Henderson, 2006, 114) (Slika 3). 


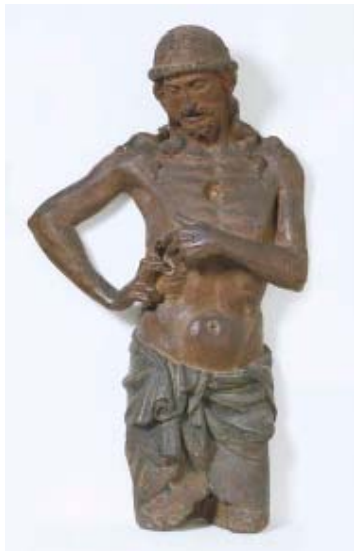

Slika 3: Kristus kaže svojo rano, ok. 1420-25,

Victoria and Albert Museum, London.

Vir: Web Gallery of Art

Že na drugem nicejskem koncilu oktobra 787 so prisotni razvoj sakralne umetnosti podprli z argumentom, da krepi izročilo katoliške Cerkve. Utemeljili so ga na konceptu prapodobe kot temelja upodabljanja svetopisemskega izročila. Češčenje se namreč ne nanaša na samo upodobitev, temveč na upodobljeno vsebino (Denzinger, 1991, 276, 278). Z razvojem mistike sta se vloga in pomen umetnin le še poglobila. Meditacijska praksa, o kateri je že bilo govora in ki se je iz samostanov razširila tudi med laiki, je temeljila na metodološkem formatu in veri v kognitivno moč domišljije, pri tem pa je s poglobljeno meditacijo na specifično doktrinarno vsebino prakticirala notranji dialog in tako delovala diskurzivno. Vključevala je tako um kot tudi emocije. Tako imenovane Andachtsbilder so v teh meditativnih praksah služile kot pripomoček za vizualizacijo teoloških vsebin. Zato je, kakor je ugotavljal Baxandall (Baxandall, 1996, 60-63), skopost likovne retorike nedvomno predstavljala zgolj prednost, saj s tem molečemu in poglobljenemu $\mathrm{v}$ kontemplacijo ni posegala $\mathrm{v}$ oblikovanje njegove mentalne podobe teoloških resnic, temveč mu je dopuščala, da te vrzeli zapolni z lastno domišlijijo (Dinzelbacher, 2004, 62). To ustvarjanje notranje podobe pa se je oblikovalo tako dolgo, dokler se v psihi molečega ni ustvarila realna podoba nevidnega sveta (Belting, 1991, 39) in se je misterij božje navzočnosti razodel tusvetni stvarnosti. Umetnina, s pomočjo katere je vernik ustvaril duhovno podobo specifičnih teoloških konceptov, je potemtakem ikoni omogočala podobno mistično funkcijo par exellence in vodila korak naprej, na najvišjo stopnjo mističnega programa, prek katere sta se stvarno in metafizično zlila v eno.

Čeprav je bila slovenjgraška cerkev sv. Duha odprta za vse meščane, ki so lahko prisostvovali bogoslužju, ki ga je izvajal tamkajšnji kaplan, in liturgičnim obredom ob 
praznikih (Mlinarič, 1986, 325), je bila vendarle namenjena predvsem oskrbovancem špitala. Tako je jasno, da funkcije poslednje sodbe v slovenjgraški špitalski cerkvi za pred njo molečega in umirajočega nikakor ni mogoče interpretirati kot opozorilo na njegovo usodo in pomen njegovih odločitev, kakor je preveč posplošeno pisal Menaše (Menaše, 1998, 130). Usoda oskrbovancev špitala in njihovega tuzemskega bivanja je bila namreč kratka in jasna. Vsi indici vodijo k domnevi, da je umetnina služila kot Andachtsbild, vendar ne glede na upodobljen motiv, slog ali način, s katerim je z gledalcem komunicirala, in ne glede na čustva, ki jih je vzbujala, temveč v tem primeru tudi glede na to, s kom je komunicirala.

Ker je bilo trpljenje bolnih, oslabelih in umirajočih oskrbovancev slovenjgraškega špitala, ki kljub boleznim praviloma niso bili deležni medicinske oskrbe, podobno Kristusovemu, pa tudi trpljenju mučenikov, je prepričanje, da fizično trpljenje zagotovo vodi v odrešitev, ki se je uveljavilo tudi med laiki, vplivalo tudi na sprejemanje njihovega lastnega trpljenja. Nedvomno je, da so uteho in odrešitev iskali v molitvi, saj so bili, kot priča ustanovna listina, vsi oskrbovanci dolžni prisostvovati bogoslužju in moliti za svoje duše ter duše donatorjev in dobrotnikov (Mlinarič, 1986, 37). Ob poglobljeni molitvi, ki so jo domnevno, kakor je narekovala tedanja praksa, prakticirali tudi med samim izvajanjem liturgije, je upodobitev poslednje sodbe na slavoloku nedvomno služila kot pripomoček za ustvarjanje notranje podobe onstranskih svetov. Prav ta stvarna podoba onstranstva, podobno kot evharistija, pa je v umirajočih, trpečih in oslabelih zbujala občutek olajšanja, vere in upanja ter hkrati pričakovanja na odrešitev v večnosti in uživanja duhovnih darov onstranstva. Ta podoba je namreč postopoma skozi globoko zatopljenost in konkretiziranje upodobljene eshatološke resnice omogočila preboj in povzdig zavesti, kjer sta se stvarno in metafizično zlila $\mathrm{v}$ eno ter omogočila zrenje same nadčutne realnosti, s tem pa prek podobe Kristusa, v katerem sta se zlila tako stvarnik in stvarstvo, vstop v razsežnost sakralnega, kamor so bili moleči in meditirajoči tudi dejansko namenjeni. Avguštin je v eni izmed svojih pridig namreč zapisal: »Kristus je v prvi vrsti odrešenik, šele nato sodnik.«

Da je temu tako, potrjuje izbira celotnega ikonografskega programa poslikave špitalske cerkve, tako motiva poslednje sodbe kot tudi sedemindvajsetih prizorov Kristusovega pasijona. A ker so ti na severni steni prezbiterija, kamor laiki praviloma niso stopali, in jih $\mathrm{z}$ ladijske strani zakriva slavoločna stena, se odpira vprašanje, komu so bili pravzaprav namenjeni.

Ali je v okviru problematike samega termina in klasifikacije tovrstnih umetnin o gledalcu mogoče govoriti kot o novem kriteriju, ki ga bo v prihodnje vredno upoštevati, bodo pokazale šele nadaljnje raziskave. Kljub temu pa je pričujoča študija pripeljala do 
drugih izjemno pomembnih ugotovitev - v prvi vrsti do ugotovitve, da je mogoče tudi $\mathrm{v}$ slovenskem prostoru zaslediti nabožne umetnine večjega formata in javnega značaja, ki so služile $\mathrm{v}$ meditativne namene, kar nas ne izključuje iz umetnostnih tendenc $\mathrm{v}$ zahodnoevropskem prostoru, nedvomno pa nakazuje na nujnost nadaljnjih raziskav, ki bi morda pripeljale še do drugih umetnin s to funkcijo. Že Stele je poudaril, da sta terminologija in samo področje nabožnega slikarstva v slovenskem prostoru vse premalo raziskana. Poleg tega je treba izpostaviti predvsem potrebo po širšem in drugačnem pristopu; iz pričujočega članka je namreč razvidno, da se pomen same umetnine ne razkriva le v ikonografski interpretaciji upodobljenega motiva, temveč šele $\mathrm{v}$ okviru konteksta, $\mathrm{v}$ katerem se upodobljeni motivi pojavljajo in na podlagi katerega se pomensko spreminjajo. Vredno pa je opozoriti, da si tudi umetnine brez posebne umetniške vrednosti zaslužijo pozornost, v našem primeru v okviru vloge, ki jo je umetnina imela, in načina, kako je komunicirala $\mathrm{z}$ gledalcem.

\section{Bibliografija}

\section{Viri}

Augustini, S. A., De doctrina christiana, Lipsiae 1838.

Avguštin, Izpovedi (prev. A. Sovre), Celje 2003.

Cureton, W., Corpus Ignatianum, To the Ephesians, London 1849.

Evans, E., Tertullian: Adversus Marcionem (lat.-ang. izdaja), Oxford 1972.

\section{Literatura}

Arbesmann, R., The Concept »Christus medicus« in St. Augustine, Traditio 10, 1954.

Baxandall, M., Slikarstvo in izkušnja v Italiji XV. stoletja, Ljubljana 1996.

Belting, H., Slika in njeno občinstvo v srednjem veku, Ljubljana 1991.

Berliner, R., Arma Christi, Münchner Jahrbuch der bildenden Kunst, III, 6. del, 1955.

Bird, J., Medicine for Body and Soul: Jacques de Vitry's Sermons to Hospitallers and their Charges, v: Religion and Medicine in the Middle Ages (ur. Biller, P. in drugi), Suffolk 2001.

Bowers, B. S., The Medieval Hospital and Medical Practise, Aldershot, Burlington 2007.

Curk, J., Gradbeni oris mestne župne cerkve in meščanskega špitala v Slovenj Gradcu, Časopis za zgodovino in narodopisje 2, Maribor 1986.

Dehio, G., Geschichte der deutschen Kunst, Berlin, Leipzig 1921. 
Denzinger, H., Kompendium der Glaubensbekenntnisse und kirchlichen Lehrentscheidungen (lat.-nem. izdaja), Freiburg im Breisgau 1991.

Dinzelbacher, P., Religiöses Erleben vorbildender Kunst in autobiographischen und biographischen Zeugnissen des Hoch- und Spätmittlelalters, v: Images of Cult and Devotion (ur. Kaspersen, S., Haastrup, U.), Gylling 2004.

Dörnemann, M., Einer ist Arzt, Christus, http://www.antikes-christentum.de/uploads/ media/zac-2013-0006____.pdf [3. 2. 2014].

Dörnemann, M., Krankheit und Heilung in der Theologie der frühen Kirchenväter, Tübingen 2003.

Elliot, J. in drugi, The Church of Santa Maria Donna Regina: Art, Iconography and Patronage in Fourteenth-Century Naples, Aldershot, Burlington 2004.

Gilchrist, R., Medieval Life: Archeology, and the Life Course, Woodbridge 2012.

Givens, J. A. in drugi, Visualizing Medieval Medicine and Natural History, 1200-1550, Aldershot, Burlington 2006.

Gurjewitsch, A. J., Das Weltbild des mittelalterlichen Menschen, München 1997.

Habsburg, M. von in drugi, Catholic and Protestant Translations of the Imitatio Christi, 1425-1650, Farnham 2011.

Henderson, J., The Renaissance Hospital: Healing the Body and Healing the Soul, London 2006.

Höfler, J., Srednjeveške freske v Sloveniji, 4. knjiga, Ljubljana 2004.

Karnes, M., Imagination, Meditation and Cognition in the Middle Ages, Chicago 2011.

Kugler, F., Handbuch der Geschichte der Malerei in Italien, Berlin 1837.

Lindberg, C., Beyond Charity: Reformation Initiatives for the Poor, Minneapolis 1993.

Lukken, M. G., Original Sin in the Roman Liturgy, Leiden 1973.

Medieval Spirituality, http://www.biblicalstudies.org.uk/pdf/bq/27-5_194.pdf [3. 2. 2014].

Menaše, L., Po sledovih renesans, v: Umetnost na Slovenskem: od prazgodovine do danes (ur. Bernik, S. in drugi), Ljubljana 1998.

Mlinarič, J., Slovenjegraški meščanski špital, Časopis za zgodovino in narodopisje 2, Maribor 1986.

Mlinarič, J. in drugi, Slovenjgraški meščanski špital v srednjem veku, Pokrajinski arhiv Maribor, Maribor 1985.

Muhovič, J., Umetnost in religija, Ljubljana 2002.

Panofsky, E., »Imago Pietatis«. Ein Beitrag zur Typengeschichte des »Schmerzensmanns« und der »Maria Mediatrix«, Leipzig 1927. 
Pohle, J., Grace, Actual and Habitual, Toronto 1919, http://www.p-books.com/read/ Grace_Actual_and_Habitual_11.html[3.2.2014].

Rawcliffe, C., Medieval English Hospital and the Quest for Spiritual Health, v: Religion, Health and Suffering (ur. Hinnells, J. R. in drugi), Oxon 2011.

Ringbom, S., Icon to Narrative: The Rise of Dramatic Close-up in Fifteenth-Century Devotional Painting, Doornspijk 1984.

Schnaase, K., Geschichte der bildenden Künste im Mittelalter, 6. del, Düsseldorf 1861.

Sedej, I., Sto najlepših cerkva na Slovenskem, Ljubljana 1996.

Stele, F., Cerkveno slikarstvo: o njegovih problemih, načelih in zgodovini, Celje 1934.

Stele, F., Gotsko stensko slikarstvo, Ljubljana 1972.

Suckale, R., »The Freedom of Medieval Art« und andere Studien zum christlichen Bild, Berlin 2003.

Suckale, R., Stil und Funktion: ausgewählte Schriften zur Kunst des Mittelalters, München 2003.

Zadnikar, M., Spomeniki cerkvene arhitekture in umetnosti, Celje 1973. 
Nadja Bartol

\section{Poslednja sodba v špitalski cerkvi sv. Duha v Slovenj Gradcu kot likovni medij sovpadanja stvarnega in metafizičnega}

Ključne besede: poslednja sodba, špitalska cerkev sv. Duha, Andachtsbild, špital

Pričujoči članek se ukvarja z motivom poslednje sodbe, upodobljenim na ladijski strani slavoločne stene v špitalski cerkvi sv. Duha v Slovenj Gradcu. Z razvojem mistike so se pojavile funkciji ikon slične upodobitve, Andachtsbilder, ki so nudile možnost kontemplativne poglobitve vernika $\mathrm{v}$ upodobljeno vsebino. Vendar pa so novejše raziskave pripeljale do ugotovitev, da so to funkcijo nosile prav tako tudi druge upodobitve večjega formata in javnega značaja. Ena izmed umetnin s to funkcijo je tudi upodobitev poslednje sodbe v špitalski cerkvi v Slovenj Gradcu. Kontekst v katerem se motiv pojavlja nedvomno osvetljuje in utemeljuje vlogo omenjene poslikave kot pripomočka za vizualizacijo svetov onstranstva, ki so jo oskrbovanci špitala, kakor je narekovala tedanja molitvena praksa, izvajali tudi med samo liturgijo. Rezultati raziskave pa so prav tako tudi pokazali, da slovenski prostor nikakor ni bil izključen iz umetnostnih tendenc $\mathrm{v}$ zahodni Evropi, kar nakazuje na nujnost nadaljnjih tovrstnih raziskav. Hkrati pa prav tako tudi opozarja na pomembnost vzpostavitve ustreznega okvirja za interpretacijo samega motiva. 
Nadja Bartol

\section{Last Judgement in the Hospital Church of the Holy Spirit in Slovenj Gradec as a Medium of Coalescence of the Real and the Metaphysical}

Keywords: Last Judgement, hospital church of the Holy Spirit, devotional image, hospital.

The article discusses the Last Judgement in the Church of the Holy Spirit in Slovenj Gradec, focussing on its function as a devotional image. The contemporary spread of mysticism was accompanied by specific icon-like devotional images, and such holds true also for the Last Judgement fresco. The church which houses it was closely connected with the activities of the nearby hospital, whose main concern was pro cura animarum, to prepare the soul for the blessings of paradise. In other words, with little earthly hope the sick and the poor had to endure pain and suffering as they prepared for the afterlife. However, this suffering was seen as a guarantee of their salvation, by means of imitatio Christi. The fresco served as an Andachtsbild, and while observing it, the sickly felt relief and consolation and, at least for a while, tasted the sweetness of heavenly realms. 